\title{
The Impact of Varicocelectomy on Testicular Arterial Blood Flow
}

\author{
Mohamed Nabil Amin, Hamdy M. Ibrahim, Khaled M. Mohamed, Hossam A. Shaker \\ Department of Urology - Faculty of Medicine Fayoum University
}

\section{Corresponding author:}

Mohamed Nabil

Amin

Mobile:

01145661222

Email:

Dr_mohamed_nabil_amin@ hotmail.co.uk

\begin{abstract}
Background: The estimated incidence of varicocele is about $20 \%$ in the general population almost $40 \%$ in subfertile men. Aim of the Work: to study the effect of loupe assisted sub varicocelectomy on the blood flow of the testicular artery, intratesticular artery and capsula before and after three months after the operation and correlated these changes with the impr of semen parameters. Patients and Methods: 30 patients were included in this study. 27 with bilateral varicocele and 3 patients with only left -sided varicocele. Clinical grading of $v \varepsilon$ in both sides was done before the operative procedures. Scrotal color Doppler ultrason measurements of vein diameter, reflux with valsalva maneuver, and peak systolic velocity end diastolic velocity (EDV) and resistive index (RI) for testicular, intratesticular and arteries were done for all patients before and three months after varicocelectomy. Results: Ir sided varicocele, loupe assisted sub inguinal varicocelectomy resulted in statistically si increase in PSV and EDV values for both testicular and intratesticular arteries and si decrease of RI for both testicular and intratesticular arteries. About the capsular branch, sta significant decrease for PSV value, EDV value and RI, 3 months after the operation; whi right-sided varicocele, our procedure resulted in highly significant increase in both PSV a: values of both testicular artery and intratesticular arteries and significant decrease of RI testicular and intratesticular arteries. About the capsular branch, statistically significant dec1 PSV value, EDV value and RI, 3 months after the varicocelectomy operation. Conclusi blood flow velocity of the testicular artery (PSV, EDV) increases after microsurgical sub varicocelectomy whereas the RI of the testicular artery decrease. This finding indicates microsurgical varicocelectomy resulted in increases the blood flow into the testis and decre resistance against the blood flow into the testis. We suggest that testicular blood flow param be used in postoperative follow-up of patients with varicocele. In addition, there is a si correlation between the improved testicular arterial blood flow and improvement in parameters after the operation.
\end{abstract}

Key words: Varicocelectomy, testicular artery, blood flow

\section{Introduction}

Varicocele is defined as a pathological dilation of the testicular panpiniform venous plexus draining the testis and present in approximately $15 \%$ of the general male population. The majority of men with varicocele are a symptomatic and fertile, with nearly $15-20 \%$ suffering from physical discomfort or problems related to fertility ${ }^{(\mathbf{1})}$.

The pathogenic mechanism through which varicocele causes testicular dysfunction and alternation in spermatogenesis is not understood (2). Some researchers reported that the impaired venous drainage causes increase in venous stasis and a decrease in arterial blood flow, inducing hypoxia and deficiency in testicular microcirculation ${ }^{(3)}$. Previous studies indicate that color Doppler ultrasonography (CDUS) is well equipment to illustrate macro-microvasculaity. The arterial flow velocities peak systolic velocity (PSV), end diastolic velocity (EDV) and the resistance indices (RI) and pulsatitily index (PI) in the testis can be measured with this technique ${ }^{(\mathbf{4})}$.

Although multiple treatment modalities exist, including radiographic embolization, laparoscopy, open sublingual microsurgical varicococelectomy is the gold standard of treatment for this condition (5) 
Some authors noticed that significant improvement occurred in testicular blood supply and sperm parameters after subinguinal microsurgical varicocelectomy (6). These improvement in both testicular blood supply and sperm parameters confirm the hypothesis that the association between varicocele and abnormal sperm parameters may depend on decreasing in testicular blood flow. On the other hand, some authors showed that testicular blood flow decreased in infertile male with varicocele ${ }^{(7)}$.

\section{Aim of the Work:}

The present study aims to investigate the effect if microsurgical subingunial varicocelectomy on testicular arterial flow using color Doppler ultasonography.

\section{Patients and Methods}

This prospective interventional study was conducted on 30 patients admitted in Urology Department, Fayoum University hospital and indicated for varicocelectomy. An informed consent has been obtained from all the subjects according to the regulation of the ethical committee of Fayoum faculty of medicine.

The study included patients with ages between 20 to 50 years, diagnosed by 1ry / 2ry infertility and 1ry varicocele with reflux, all grades of varicocele.

While subjects older than 50 yrs., or less 20 years, alcoholics, heavy smokers and drug abusers will be excluded from this study, patients suffering from any systemic diseases may have effect on the arterial flow like Diabetes, hypertension, liver disease and hypercholesterolemia, patients who underwent previous Varicocelectomy operations or inguinoscrotal operation on the same side, patients who have past history of arterial or any peripheral vascular disease (e.g.: atherosclerosis), ptients with past history of genitourinary trauma or infection(Mumps) and Azoospermia patients with high FSH (more than triple normal) were excluded from the study.

\section{Methods}

\section{Preoperative assessment}

Detailed history taking, both present and past history stressing on sexual history, conceptional history, previous surgical procedures in inguinoscrotal area and social history.

\section{Physical examination}

General examination stressing on: ageappropriate development of male secondary sex characteristics Gynecomastia (due to hormonal effect) evaluation for lesions or scarring to the abdomen or groin Local examination stressing on: The scrotum must be carefully and thoroughly palpated, and the presence of all scrotal structures should be confirmed, along with their size and consistency. Masses may arise from the surface of the testicle, adjacent to or separate from the testes. Testicular tenderness, size, consistency, and any swellings. Epididymis and the Vas for nodules, presence or absence on both sides. Palpating the Pampiniform plexus of the cord and clinical grading of the varicocele in supine and standing positions, with applying Valsalva maneuver. Grading of varicocele during physical examination was classified into four grades according to Dubin and Amelar classification, subclinical (seen on imaging but no varicocele on examination), Grade I (small, palpable with Valsalva),Grade II (moderate,palpable when standing without Valsalva), and Grade III (large,easily visible).

\section{Laboratory investigations}

At least two semen analysis according to WHO 2010 criteria will be done to all patients before and 3 months after Varicocelectomy and preoperative routine lab investigations.

Radiological examination included Scrotal U/S and Scrotal color Doppler ultrasound.

Grading of varicocele during CDUS was classified into four grades according to Dubin and Amelar classification, Grade 0 (moderate, transient venous reflux during Valsalva maneuver which is a physiological finding), Grade I (persistent venous reflux that ends before the Valsalva maneuver is completed), Grade II (persistent venous reflux throughout the entire Valsalva maneuver), and Grade III (venous reflux that is present under basal conditions and doesn't change during the Valsalva maneuver). 
Arterial blood flows of the right and left testicular arteries and their capsular and intratesticular branches in varicocele patients before and after microsurgical subinguinal varicocelectomy were measured and analyzed by color Doppler ultrasonography. The testicular artery was observed at the proximal end of the testis where it enters the testis, the capsular branch at the periphery of the testis, and the intratesticular branch in the parenchymal of the testis.

\section{Operative parameters:}

All patients have been subjected to sub inguinal varicocelectomy under spinal/general anesthesia if indicated, using loop magnification power technique $(3.5 \mathrm{x})$. a $2-3-\mathrm{cm}$ sub inguinal oblique skin incision was done over the external inguinal ring. The incision is deepened through Camper's and Scarpa's fasciae and the spermatic cord is then grasped with a Babcock clamp. The external pudendal collaterals were ligated (if present). the spermatic fascia $\mathrm{w}$ grasped and opened, and the vas deferens and associated vessels were preserved. At least one spermatic artery and three lymphatic vessels were divided and preserved. All veins within the spermatic cord were doubly ligated with 2-0 vicryl ties and divided. Subcutaneous tissues were closed with interrupted 2-0 Vicryl sutures, and the skin was closed using a running subcuticular 2-0 absorbable vicryl suture.

\section{Statistical analysis:}

Data were statistically described in terms of mean \pm standard deviation $( \pm$ SD), and range, or frequencies (number of cases) and percentages when appropriate. Comparison between pre- and postoperative results was done using paired test for matched samples. $\mathrm{p}$ values less than 0.05 was considered statistically significant. All statistical calculations were done using computer program IBM SPSS (Statistical Package for the Social Science; IBM Corp, Armonk, NY, USA) release 22 for Microsoft Windows.

\section{Results}

\section{Clinical grading of varicocele:}

Preoperative assessment of grading of left sided varicocele by clinical examination in thirty patients was as follows: 3 patients (10\%) had grade I, 7 patients $(23.3 \%)$ had grade II and 20 patients $(66.7 \%)$ had grade III.

Preoperative assessment of grading of right sided varicocele by clinical examination in thirty patients revealed: 7 patients $(23.3 \%)$ had grade I, 12 patients (40 \%) had grade II and 8 patients $26.7 \%$ had grade III and 3 patients had no varicocele on the right side $(10 \%)$. (table 1).

\section{Ultrarasonographic grading of varicocele:}

Preoperative assessment of different grades in patients with left sided varicocele $(n=$ 30) by color Doppler ultrasonography revealed 3 Patients (10\%) with (grade I), 7 patients $(23.3 \%)$ with (grade II) and 20 patients $(66.7 \%)$ with (grade III).

Preoperative assessment of the right side varicocele patients $(\mathrm{n}=30)$ by color Doppler ultrasonography revealed 7 patients $(23.3 \%)$ with (grade I), 11 patients (36.7\%) with (grade II), and 9 patients $(20 \%)$ with (grade III) and 3 patients $(10 \%)$ with (grade O). (table 1)

Table (1): Preoperative characteristics of the study sample.

\begin{tabular}{|c|c|}
\hline \multicolumn{1}{|c|}{ Item } & Value \\
\hline Age (years)* & $31.43 \pm 6.1$ \\
\hline $\begin{array}{c}\text { Laterality of the varicocele: } \\
-\quad \text { Left side only }\end{array}$ & $3(10 \%)$ \\
$-\quad$ Bilateral (right and left) & $27(90 \%)$ \\
\hline $\begin{array}{c}\text { Clinical grade of Rt side: }:^{\dagger} \\
-\quad \text { No }\end{array}$ & $3(10 \%)$ \\
\hline
\end{tabular}


ISSN: 2536-9482 (Online) Fayoum University Medical Journal Amin et al., 2021,4(1), 1-11

\begin{tabular}{|c|c|}
\hline $\begin{array}{ll}- & \text { Grade 1 } \\
\text { - } & \text { Grade 2 } \\
\text { - } & \text { Grade 3 }\end{array}$ & $\begin{array}{c}7(23.4 \%) \\
12(40.0 \%) \\
8(26.7 \%)\end{array}$ \\
\hline $\begin{array}{cl}\text { Clinical } & \text { grade of Lt side: } \\
\text { - } & \text { No } \\
\text { - } & \text { Grade 1 } \\
\text { - } & \text { Grade 2 } \\
- & \text { Grade 3 }\end{array}$ & $\begin{array}{c}0(0.0 \%) \\
3(10 \%) \\
7(23.3 \%) \\
20(66.7 \%)\end{array}$ \\
\hline $\begin{array}{cl}\text { Grade }^{\text {of reflux on Rt side: }}{ }^{\dagger} & \text { No } \\
- & \text { Grade 1 } \\
- & \text { Grade 2 } \\
- & \text { Grade 3 }\end{array}$ & $\begin{array}{c}3(10 \%) \\
7(23.3 \%) \\
11(36.7 \%) \\
9(30 \%)\end{array}$ \\
\hline $\begin{array}{cl}\text { Grade of reflux on Lt side: } & { }^{\dagger} \\
- & \text { No } \\
- & \text { Grade 1 } \\
- & \text { Grade 2 } \\
- & \text { Grade } 3\end{array}$ & $\begin{array}{c}0(0.0 \%) \\
3(10 \%) \\
7(23.3 \%) \\
20(66.7 \%)\end{array}$ \\
\hline
\end{tabular}

$*$ data is represented in mean $\pm \mathrm{SD} ; \dagger$ data is represented in number of cases $(\%)$

\section{Testicular volume:}

- The mean testicular volumes of the patients before the operation was $18.8 \mathrm{ml} \pm 4.6$ in the right testis and $17.8 \mathrm{ml} \pm 3.9$ in the left testis

- The mean testicular volumes of the patients 3 months after the operation was $18.9 \mathrm{ml} \pm 4.2$ in the right testis and $17.9 \mathrm{ml} \pm 2.6$ in the left testis (table 2).

- No signification difference in the testicular volumes between varicocele patients, before and after subinguinal varicocelcectomy.

Table (2): illustrates the average testicular volumes of patients before and after subinguinal varicocelectomy.

\begin{tabular}{|c|c|c|}
\hline Patients & Rt side & Left side \\
\hline Before operation & $18.8 \mathrm{ml} \pm 4.6$ & $17.8 \mathrm{ml} \pm 3.9$ \\
3 months After operation & $18.9 \mathrm{ml} \pm 4.2$ & $17.9 \mathrm{ml} \pm 2.6$ \\
\hline
\end{tabular}

\section{Semen Analysis:}

The mean semen parameters of the patients before the operation $(n=30)$ involved in this study: sperm count was 16.58 million per milliliter, motility was $29.0 \%$ and abnormal morphology was $55.0 \%$ (tables 3,4,5).

Semen parameters of the patients (3 months after sub inguinal varicocelectomy) showed statistically insignificant improvement were observed in sperm count 19.73 million per milliliter $(p=0.133)$, however highly significant improvement in motility 43.9\% $(p<0.001)$ and decrease of the abnormal morphology percentage 35\% ( $\mathrm{p}<0.001)$ (tables $\mathbf{3 , 4 , 5}$ ).

Table (3): Comparison of sperm concentration (million per ml) between the study groups

\begin{tabular}{|l|c|c|c|}
\hline & Pre-treatment & 3m after treatment & p value \\
\hline Number of cases & 30 & 30 & \\
\cline { 1 - 3 } Mean & $16.58 \mathrm{mill} / \mathrm{ml}$ & $19.73 \mathrm{mill} / \mathrm{ml}$ & \multirow{2}{*}{0.133 (NS) } \\
\cline { 1 - 3 } SD & 24.29 & 22.94 & \\
\hline
\end{tabular}

NS: insignificant difference

Table (4): Comparison of progressive motility percentage between the study groups

\begin{tabular}{|l|c|c|c|}
\hline & Pre-treatment & 3m after treatment & p value \\
\hline Number of cases & 30 & 30 & \multirow{2}{*}{$<0.001(\mathrm{HS})$} \\
\hline Mean & $29.0 \%$ & $43.9 \%$ & \\
\hline
\end{tabular}


ISSN: 2536-9482 (Online) Fayoum University Medical Journal Amin et al., 2021,4(1), 1-11

HS: highly significant difference

Table (5): Comparison of abnormal forms percentage between the study groups

\begin{tabular}{|l|c|c|c|}
\hline & Pre-treatment & 3m after treatment & p value \\
\hline Number of cases & 30 & 30 & \\
\cline { 1 - 3 } Mean & $55.0 \%$ & $35.6 \%$ & $<0.001(\mathrm{HS})$ \\
\cline { 1 - 3 } SD & $27.0 \%$ & $11.1 \%$ & \\
\hline
\end{tabular}

HS: highly significant difference

\section{Operative analysis of arterial blood values (PSV, EDV and RI values) by color Doppler ultrasonography:}

- In the left sided varicocele, PSV, EDV and RI values were $(16.26 \mathrm{~cm} / \mathrm{sec}, 4.56 \mathrm{~cm} / \mathrm{sec}, 0.71)$ for testicular artery, $(13.0 \mathrm{~cm} / \mathrm{sec}, 4.42 \mathrm{~cm} / \mathrm{sec}, 0.65)$ for intratesticular artery, and $(13.94 \mathrm{~cm} / \mathrm{sec}, 4.87$ $\mathrm{cm} / \mathrm{sec}, 0.65$ ) for capsular artery respectively. Repair of the varicocele by microsurgical subinguinal varicocelectomu resulted in statistically significant increase in PSV and EDV values for both testicular $(19.43 \mathrm{~cm} / \mathrm{sec}, 6.93 \mathrm{~cm} / \mathrm{sec})$ and intratesticular arteries $(15.92 \mathrm{~cm} / \mathrm{sec}, 6.54 \mathrm{~cm} / \mathrm{sec})$ and significant decrease of RI for both testicular (0.64) and intratesticular (0.58) arteries. About the capsular branch, statistically significant decrease for PSV value $(11.29 \mathrm{~cm} / \mathrm{sec})$, EDV value (4.56 $\mathrm{cm} / \mathrm{sec}$ ) and RI (0.59) 3 months after the operation (tables 6,7,8,9,10,11,12,13,14).

Table (6): Comparison of left testicular artery PS (cm/sec.) between the study groups

\begin{tabular}{|l|c|c|c|}
\hline & Pre-treatment & 3m after treatment & p value \\
\hline Number of cases & 30 & 30 & \multirow{2}{*}{$<0.001$ (HS) } \\
\cline { 1 - 3 } Mean & 16.26 & 19.43 & \\
\hline
\end{tabular}

HS: highly significant difference

Table (7): Comparison of left testicular artery ED (cm/sec.) between the study groups

\begin{tabular}{|l|c|c|c|}
\hline & Pre-treatment & 3m after treatment & p value \\
\hline Number of cases & 30 & 30 & \\
\hline Mean & 4.56 & 6.93 & $<0.001$ (HS) \\
\hline SD & 1.21 & 1.84 & \\
\hline
\end{tabular}

HS: highly significant difference

Table (8): Comparison of left testicular artery RI between the study groups

\begin{tabular}{|l|c|c|c|}
\hline & Pre-treatment & 3m after treatment & p value \\
\hline Number of cases & 30 & 30 & \multirow{2}{*}{$<0.001$ (HS) } \\
\cline { 1 - 3 } Mean & 0.70 & 0.64 & \\
\hline SD & 0.07 & 0.09 & \\
\hline
\end{tabular}

HS: highly significant difference

Table (9): Comparison of left intra-testicular artery PS (cm/sec.) between the study groups

\begin{tabular}{|l|c|c|c|}
\hline & Pre-treatment & 3m after treatment & p value \\
\hline Number of cases & 30 & 30 & \multirow{2}{*}{$<0.001(\mathrm{HS})$} \\
\cline { 1 - 3 } Mean & 13.00 & 15.92 & \\
\hline SD & 3.87 & 4.80 & \\
\hline
\end{tabular}

HS: highly significant difference

Table (10): Comparison of left intra-testicular artery ED (cm/sec.) between the study groups

\begin{tabular}{|l|l|l|l|}
\hline & Pre-treatment & 3m after treatment & p value \\
\hline
\end{tabular}




\begin{tabular}{|l|c|c|c|}
\hline Number of cases & 30 & 30 & \\
\cline { 1 - 3 } Mean & 4.42 & 6.54 & $<0.001$ (HS) \\
\hline SD & 1.01 & 2.02 & \\
\hline
\end{tabular}

HS: highly significant difference

Table (11): Comparison of left intra-testicular artery RI between the study groups

\begin{tabular}{|l|c|c|c|}
\hline & Pre-treatment & 3m after treatment & \multicolumn{1}{c|}{ p value } \\
\hline Number of cases & 30 & 30 & \multirow{2}{*}{$<0.001(\mathrm{HS})$} \\
\hline Mean & 0.65 & 0.58 & \\
\hline SD & 0.06 & 0.04 & \\
\hline
\end{tabular}

HS: highly significant difference

Table (12): Comparison of left capsular artery PS (cm/sec.) between the study groups

\begin{tabular}{|l|c|c|c|}
\hline & Pre-treatment & 3m after treatment & p value \\
\hline Number of cases & 30 & 30 & \multirow{2}{*}{$<0.001$ (HS) } \\
\cline { 1 - 3 } Mean & 13.94 & 11.29 & \\
\hline SD & 3.54 & 2.56 & \\
\hline
\end{tabular}

HS: highly significant difference

Table (13): Comparison of left capsular artery ED ( $\mathrm{cm} / \mathrm{sec}$.) between the study groups

\begin{tabular}{|l|c|c|c|}
\hline & Pre-treatment & 3m after treatment & p value \\
\hline Number of cases & 30 & 30 & \\
\hline Mean & 4.87 & 4.56 & \multirow{2}{*}{0.127 (NS) } \\
\hline SD & 1.23 & 1.09 & \\
\hline
\end{tabular}

NS: insignificant difference

Table (14): Comparison of left capsular artery RI between the study groups

\begin{tabular}{|l|c|c|c|}
\hline & Pre-treatment & 3m after treatment & p value \\
\hline Number of cases & 30 & 30 & \multirow{2}{*}{$<0.001$ (HS) } \\
\hline Mean & 0.65 & 0.59 & \\
\hline SD & 0.06 & 0.06 & \\
\hline
\end{tabular}

HS: highly significant difference

In the right- sided varicocele, PSV, EDV and RI values were $(15.1 \mathrm{~cm} / \mathrm{sec}, 5.04 \mathrm{~cm} / \mathrm{sec}, 0.67)$, for testicular artery and $(12.94 \mathrm{~cm} / \mathrm{sec}, 4.45 \mathrm{~cm} / \mathrm{sec}, 0.64)$ for intratesticular artery, $(13.77 \mathrm{~cm} / \mathrm{sec}, 5.06$ $\mathrm{cm} / \mathrm{sec}, 0.62$ ) for capsular artery. Microsurgical subinguinal varicocelectomy resulted in highly significant increase in both PSV and EDV values of both testicular artery $(18.34 \mathrm{~cm} / \mathrm{sec}, 7.21 \mathrm{~cm} / \mathrm{sec})$ and intratesticular artery $(16.26 \mathrm{~cm} / \mathrm{sec}, 6.85 \mathrm{~cm} / \mathrm{sec})$ and significant decrease of RI for both testicular (0.6) and intratesticular (0.57) arteries. About the capsular branch, statistically significant decrease for PSV value $(11.09 \mathrm{~cm} / \mathrm{sec})$, EDV value $(4.61 \mathrm{~cm} / \mathrm{sec})$ and RI $(0.577) 3$ months after the varicocelectomy operation (tables 15,16,17,18,19,20,21,22,23)

Table (15): Comparison of right testicular artery PS (cm/sec.) between the study groups

\begin{tabular}{|l|c|c|c|}
\hline & Pre-treatment & 3m after treatment & p value \\
\hline Number of cases & 30 & 30 & \\
\cline { 1 - 3 } Mean & 15.07 & 18.34 & \multirow{2}{*}{$<0.001(\mathrm{HS})$} \\
\cline { 1 - 3 } SD & 4.85 & 5.03 & \\
\hline
\end{tabular}

HS: highly significant difference

Table (16): Comparison of right testicular artery ED (cm/sec.) between the study groups

\begin{tabular}{|l|c|c|c|}
\hline & Pre-treatment & 3m after treatment & p value \\
\hline Number of cases & 30 & 30 & $<0.001$ (HS) \\
\hline Mean & 5.04 & 7.21 & $<$ \\
\hline
\end{tabular}


ISSN: 2536-9482 (Online) Fayoum University Medical Journal Amin et al., 2021,4(1), 1-11

HS: highly significant difference

Table (17): Comparison of right testicular artery RI between the study groups

\begin{tabular}{|l|c|c|c|}
\hline & Pre-treatment & 3m after treatment & p value \\
\hline Number of cases & 30 & 30 & \multirow{2}{*}{$<0.001(\mathrm{HS})$} \\
\cline { 1 - 3 } Mean & 0.67 & 0.60 & \\
\hline
\end{tabular}

HS: highly significant difference

Table (18): Comparison of right intra-testicular artery PS (cm/sec.) between the study groups

\begin{tabular}{|l|c|c|c|}
\hline & Pre-treatment & 3m after treatment & p value \\
\hline Number of cases & 30 & 30 & \multirow{2}{*}{$<0.001(\mathrm{HS})$} \\
\cline { 1 - 3 } Mean & 12.94 & 16.26 & 3.49 \\
\hline
\end{tabular}

HS: highly significant difference

Table (19): Comparison of right intra-testicular artery ED (cm/sec.) between the study groups

\begin{tabular}{|l|c|c|c|}
\hline & Pre-treatment & 3m after treatment & \multicolumn{1}{|c|}{ p value } \\
\hline Number of cases & 30 & 30 & \multirow{2}{*}{$<0.001$ (HS) } \\
\hline Mean & 4.45 & 6.85 & \\
\hline SD & 1.07 & 1.54 & \\
\hline
\end{tabular}

HS: highly significant difference

Table (20): Comparison of right intra-testicular artery RI between the study groups

\begin{tabular}{|l|c|c|c|}
\hline & Pre-treatment & 3m after treatment & p value \\
\hline Number of cases & 30 & 30 & \\
\cline { 1 - 3 } Mean & 0.64 & 0.57 & \multirow{2}{*}{$<0.001(\mathrm{HS})$} \\
\cline { 1 - 3 } SD & 0.06 & 0.04 & \\
\hline
\end{tabular}

HS: highly significant difference

Table (21): Comparison of right capsular artery PS (cm/sec.) between the study groups

\begin{tabular}{|l|c|c|c|}
\hline & Pre-treatment & 3m after treatment & p value \\
\hline Number of cases & 30 & 30 & \\
\cline { 1 - 3 } Mean & 13.77 & 11.09 & \multirow{2}{*}{$0.001(\mathrm{HS})$} \\
\cline { 1 - 3 } & 4.02 & 3.02 & \\
\hline
\end{tabular}

HS: highly significant difference

Table (22): Comparison of right capsular artery ED (cm/sec.) between the study groups

\begin{tabular}{|l|c|c|c|}
\hline & Pre-treatment & 3m after treatment & p value \\
\hline Number of cases & 30 & 30 & \multirow{2}{*}{$0.124(\mathrm{NS})$} \\
\cline { 1 - 3 } Mean & 5.06 & 4.61 & \\
\hline
\end{tabular}

NS: insignificant difference

Table (23): Comparison of right capsular artery RI between the study groups

\begin{tabular}{|l|c|c|c|}
\hline & Pre-treatment & 3m after treatment & p value \\
\hline Number of cases & 30 & 30 & \multirow{2}{*}{$<0.001$ (HS) } \\
\hline Mean & 0.62 & 0.58 & 0.05 \\
\hline SD & 0.07 & 05 & \\
\hline
\end{tabular}

HS: highly significant difference

Operative and post-operative outcome: 
By loop (3.5X) magnification power, the testicular artery and accompanied lymphatics could be easily visualized, identified and spared during the operative procedures.

Three patients had complications that reported as following (one with right sided hematoma,two with skin wound infection) which has been managed with proper care scrotal elevation and proper antibiotics.

No other relapses or complications (i.e. fever, hematoma, wound infection, hydrocele formation or testicular atrophy) was seen early postoperative or within 3 month follow up of all patients $(n=30)$ included in this study.

\section{Discussion}

Color Doppler ultrasonography (CDUS) is one of the most reliable and rapid methods of measuring blood flow; combining anatomical and velocity data and providing a rapid assessment in routine studies ${ }^{(\mathbf{8 , 9})}$. Doppler indices have been used to obtain information about blood flow and vascular impedance that cannot be obtained from velocity information alone. These indices depend on the measurements of PSV and EDV. Middleton et al. (10) evaluated the Doppler characteristics of intratesticular, testicular and capsular arteries. they showed that the wave from of the intratesticular artery had high diastolic flow, whereas velocity wave forms from the testicular arteries were variable. This variability was attributed to sampling of different vessels and they hypothesized that the high resistance wave forms obtained in the supratesticular region originated from the cremasteric and defferential arteries.

The widely used index is resistive index (RI). Aziz et al. (11) evaluated the spermatic cord arteries in men with normal testes using color Doppler ultrasonography (CDUS). they identified 3 arteries within the spermatic cord and established reference values for the RI of these arteries and showed that one artery consistently have lower RI than the other 2 arteries.

For the measurement of intratesticular blood flow, the RI has been used to assess data in both animals and humans ${ }^{(\mathbf{1 2}, \mathbf{1 3}, \mathbf{1 4})}$ the measurement of testicular RI has also been used to assess testicular integrity in various previous studies. Tanriverd et al. ${ }^{(14)}$ measured testicular blood flow and the mean RI after microsurgical and high ligation varicocelectomy in 86 patients clinically diagnosed as varicocele, showing no significant impairment in testicular circulation after low micro surgical varicocele repair, compared with high ligation

By comparing varicocele group with the control group, Unsal et al. ${ }^{(15)}$ evaluated the blood supply of the capsular and intartesticular arteries and found a significant increases in RI value of the capsular artery in patients with varicocele, however, there was no difference in blood supply of the interatesticular artery. They suggested that capsular branches are larger and straighter vessels at the periphery of the testes and the velocity of the blood flow is greater than in the intratesticular branches.

A research evaluating the long term effects of varicocelectomy on testicular blood flow was done by Balci et al. ${ }^{(2)}$. In their research, however only the intratesticular artery was evaluated and the loupe assissted technique was not applied. In their research 26 infertile patients with left varicocele were operated and monitored up to the sixth months after the operation. they do not find any change in the intratesticular artery PSV values, but they reported an increase EDV and a decrease in the RI value.

In our study, however, the PSV and EDV values of both testicular and intratesticular arteries showed significant increase, RI value showed a significant decrease. PSV and EDV values showed blood flow velocity, while RI value showed resistance against blood flow. The resistive indices reflect hemodynamic changes inside the testis while PSV and EDV values reflect the testicular artery which is outside the testis. Decrease in resistive indices are indicator of blood building of the testis after the operation.

In the present study, we investigated the effect of microsurgical sub inguinal 
varicocelectomy on the testicular blood supply. Analysis of the blood flow velocities (PSV and EDV) depended on vessel diameter and the angle of insonation, while resistance indices (RI) did not depend on these factors. RI is a good indicator to evaluate smaller and more tortuous vessels than PSV and EDV. We believe that testicular blood flow velocities are assessed in the testicular artery, which has the largest diameter among the arteries feeding the testes. In the present study, significant increase in the mean PSV and EDV values of testicular artery in the testes were observed. The capsular and intratesticular branches of testicular artery are smaller and more tortuous and have lower flow velocity, their blood flow velocities (PSV and EDV) are difficult to assess but with professional Radiologist it could be assisted.

Marchesini et al. ${ }^{(16)}$ suggested that the blood supply of the small, tortuous branches should be assessed with resistive index RI. In the current study, there was a significant decrease in RI value in the capsular and intra-testicular arteries after microsurgical sub inguinal varicoceletomy. These data support the view that this operation increases the testicular microcirculation. Although blood flow velocity of testicular artery increases after sub inguinal varicocelectomy, resistance indices of the branches of the testicular artery decrease.

In the present study, we found a significant correlation between semen analysis and blood flow values (PSV, EDV, RI) of the capsular artery in patients with varicocele before the operation. The capsular branches are more reliable regarding the values of the testicular blood flow because there is a strong correlation with sperm parameters and the blood flow of capsular branches, Therefore, evaluation of the blood flow of the capsular artery using CDUS will be useful in post operative assessment of patients with varicoceletomy.

The relationship between improved sperm parameters and increased testicular blood flow was confirmed in our study because semen parameters increased after sub inguinal varicocelectomy. In a metanalysis of 14 studies comparing pre - and postoperative semen paramenters following varicoceletomy performed via either the high ligation, or subinguinal varicoceletomy. Schuster et al. ${ }^{(9)}$ documented significant and comparable improvements in sperm count and motility, regardless of the surgical technique. Similar improvement in postoperative semen parameters have been reported by many other researches ${ }^{(\mathbf{1 7}, 18,19)}$.

Decreased Sperm number, decreased motility and increased percentage of abnormal forms are all complications of varicocele that lead to decreased fertility. Increased efficacy of the cooling system causes germ cell apoptosis a leading cause of these seminal abnormalities and damage to sperm chromatin clue to increased oxidative stress and apoptosis of germ cells ${ }^{(5)}$. Varicoceletomy eliminates venous stasis and returns testicular blood flow to the original state (6)

Previous studies showed that significant increases in pregnancy rate and sperm quality when microsurgery technique was applied to varicocele treated patient ${ }^{(20)}$. The study of Orhan et al. (21) compares the subinguinal and inguinal approaches of microsurgery and revealed that there were no differences in operation time, sperm recovery or pregnancy rates; however, more arteries and veins are involved in the subinguinal approach. Therefore, because the lack of a musculofascial incision with less post-operative pain and the lowest risk of complications and the lower rate of recurrence because of the ability to ligate the cremasteric veins at this level, the loupe assisted sub inguinal varicoceleectomy technique was applied in our research.

The previous studies have suggested that abnormal semen parameters in varicocele may be associated with decrease testicular blood supply, lead to hypoxia and impaired energy production and metabolism and thus may lead to injury of spermatogenesis. Harrison et al. ${ }^{(22)}$ and Hsu et al. (23), in their experimental researches stated that varicocele reduces testicular blood supply. In human studies, Unsal et al. ${ }^{(15)}$ compared varicocele group with the control group and evaluated the blood supply of the capsular and intratesticular arteries and found a significant increase in RI wave of left capsular artery in patient with left varicocele, they suggested that capsular branches are larger and straighter vessels at the periphery of the Testes and the velocity of the blood flow is greater than in the intratesticular branches. They found a significant 
correlation between semen analysis and blood flow values RI, PSV, of the capsular artery in patient with varicocele. Tarhan et al. ${ }^{(6)}$ stated that the evaluation of the blood supply of the capsular artery using CDUS will be useful in postoperative examination of patient after the operation of varicocelectomy.in our study, surgical ligation of varicocele results in an improvement in semen parameters and a significant decrease in mean intratesticular RI, which may be due to the decrease in venous pressure after varicocele repair. The decrease in RI after varicocelectomy suggests that an improvement may occur in the testicular blood supply.

\section{Conclusion:}

The blood flow velocity of the testicular artery (PSV, EDV) increases after microsurgical subinguinal varicocelectomy whereas the RI of the testicular artery decrease. This finding indicates that the microsurgical varicocelectomy resulted in increases the blood flow into the testis and decreases the resistance against the blood flow into the testis. We suggest that testicular blood flow parameters can be used in postoperative follow-up of patients with varicocele. In addition, there is a significant correlation between the improved testicular arterial blood flow and improvement in semen parameters after the operation.

\section{References}

1. Goldstein, M. (2012): Surgical management of male infertity in: Wein A, Kavoussi LR, Novick AC. Partin AW, Peters CA. editors. Campbell-walsh urology. Philadelphia. Pa: Elsevier saunders; 2012: 648-687

2. Balci, A., Karazincir, S., Gorur, S., Sumbas, H., Egilmez, E., \& Inandi, T. (2008): Long-term effect of varicocele repair on intratesticular arterial resistance index. Journal of Clinical Ultrasound, 36(3): 148-152.

3. Ucer, O., Zeren, M. F., Tarhan, S., \& Gumus, B. (2015): Does Varicocele Affect Testicular Arterial Blood Flow?. Firat Medical Journal, 20(1), 29-32.
4. Tarhan, S.; Gümüs, B.; Gündüz, I.; Ayyildiz, V. \& Goktan, C. (2003): Effect of varicocele on testicular artery blood flow in men-color Doppler investigation. Sound J Urol Nephrol.:37(1):38-42.

5. Tatem, A. J., \& Brannigan, R. E. (2017): The role of microsurgical varicocelectomy in treating male infertility. Translational andrology and urology, 6(4):722.

6. Tarhan, S.; Ucer, O.; Sahin, M. O. \& Gumus, B. (2011): Long-Term Effect of Microsurgical Inguinal Varicocelectomy on Testicular Blood Flow. Journal of andrology, 32(1): 33-39.

7. Hassan, A., Gad, H. M., \& Mostafa, T. (2011):Radiologically assessed testicular changes in infertile males with varicocele. Andrologia, 43(5): 307-311.

8. Atilla, M. K., Sargin, H., Yilmaz, Y., Odabas, O., Keskin, A., \& Aydin, S. (1997): Undescended testes in adults: clinical significance of resistive index values of the testicular artery measured by Doppler ultrasound as a predictor of testicular histology. The Journal of urology, 158(3): 841-843.

9. Schuster, A., Frauscher, F., Strasser, H., Recheis, W., Pallwein, L., Herwig, R., \& Pinggera, G. M. (2004): Power Doppler ultrasound imaging for quantification of urinary bladder neck blood flow changes. Ultrasound in medicine \& biology, 30(10): 1379-1384.

10. Middleton, W. D., Thorne, D. A., \& Melson, G. L. (1989): Color Doppler ultrasound of the normal testis. American Journal of Roentgenology, 152(2): 293-297.

11. Aziz, Z. A., Satchithananda, K., Khan, M., \& Sidhu, P. S. (2005): High-Frequency Color Doppler Ultrasonography of the Spermatic Cord Arteries. Journal of ultrasound in medicine;24(7): 905-909.

12. Gumbsch, P., Gabler, C., \& Holzmann, A. (2002): Colour-coded duplex sonography of the testes of dogs. The Veterinary Record, 151(5): 140-144. 
13. Pozor, M. A., \& McDonnell, S. M. (2004): Color Doppler ultrasound evaluation of testicular blood flow in stallions. Theriogenology, 61(5): 799-810.

14. Tanriverdi, O.; Miroglu, C; Horasanli, K; Altay, B; Caliskan, K.C. \& Gumus E. (2006): Testicular blood flow measurements and mean resistive index values after microsurgical and high ligation varicocelectomy. Urology.;67(6): 12621265.

15. Unsal, A.; Turgut, A.T.; Ta kin, F. \& Karaman, C.Z. (2007): Resistance and pulsatility index increase in capsular branches of testicular artery: indicator of impaired testicular microcirculation in varico-cele? J Clin Ultrasound.;35(4): 191 195.

16. Marchesini, A.C.; Magrio, F.A.; Bere3owski, A.T. et al. (2008): A critical analysis of Doppler velocimetry in the differential diagnosis of malignant and bening. Fertil steril: 81(6)1585-1588

17. Baazeem, A.; Belzile, E.; Ciampi, A.; Dohle, G.; Jarvi, K.; et al. (2011) Varicocele and male factor infertility treatment: a new meta-analysis and review of the role of varicocele repair. Eur Urol; 60:796-808.
18. Abdel-Meguid, T.; Al-Sayyad, A.; Tayib, A. \& Farsi, H. (2011): Does varicocele repair improve male infertility? An evidencedbased perspective from a randomized, Controlled trial. Eur Urol; 59: 455-61.

19. Al Bakri, A.; Lo, K; Grober. E. et al. (2012): Time for improvement in semen parameters after varicocelectomy. J Urol. 2012; 187:227-31.

20. Marmar, J.L. \& Kim, Y. (1994): Subinguinal microsurgical varicocelectomy: a technical critique and statistical. analysis of semen and pregnancy data.152:1127-32.

21. Orhan, I., Onur, R., Semerciöz, A., Firdolas, F., Ardicoglu, A., \& Köksal, I. T. (2005): Comparison of two different microsurgical methods in the treatment of varicocele.Archives of andrology, 51(3):213-220.

22. Harrison, R. M., Lewis, R. W., \& Roberts, J. A. (1986): Pathophysiology of varicocele in nonhuman primates: long-term seminal and testicular changes. Fertility and sterility, 46(3): 500-510.

23. Hsu, H. S., Chang, L. S., Cheng, M. T., \& Wei, Y. H. (1994): Decreased blood flow and defective energy metabolism in the varicocele-bearing testicles of rats. European urology, 25: 71-75. 